\title{
Pain assessment of ultrasound-guided liver biopsy for diffuse parenchymal diseases: a randomized trial comparing intercostal and subcostal techniques
}

\author{
Yaşar Türk ${ }^{1,2} \odot$, Banu Alıcıoğlu²๑, İsmail Devecioğlu ${ }^{3} \odot$

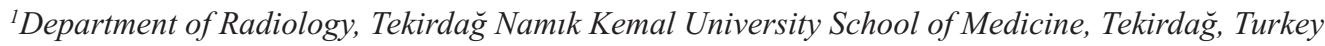 \\ ${ }^{2}$ Department of Radiology, Zonguldak Bülent Ecevit University School of Medicine, Zonguldak, Turkey \\ ${ }^{3}$ Department of Biomedical Engineering, Tekirdă̆ Namık Kemal University, Çorlu Engineering Faculty, Tekirdă̆, Turkey
}

\begin{abstract}
Objectives: Percutaneous liver biopsy is widely used in diffuse liver parenchymal diseases. Comparison of the severity of pain is not properly studied. In this randomized study, pain intensity between the intercostal and subcostal techniques of US-guided Tru-Cut liver biopsy in diffuse liver diseases was compared.

Methods: Between March 2016 and May 2017, all potential study participants referred to the interventional radiology department for ultrasound-guided liver biopsy $(\mathrm{n}=245)$, were assessed for enrollment. The pain intensity at 0,2 , and $4 \mathrm{~h}$ post-procedure was compared in two groups using a Numeric Rating Scale (NRS). Premedication was not used. After applying local anesthesia under US-guidance, 18-G automatic biopsy needle free-hand US-guided biopsy was performed.

Results: Immediately after the biopsy $(p=0.0024)$, and at the 2 nd hour $(p=0.0298)$, NRS of the subcostal group was significantly less than the intercostal group. Furthermore, the need for oral $(p=0.0492)$ or intramuscular $(p=0.0094)$ analgesics after the biopsy in the subcostal group was significantly less than the intercostal group. At the evaluation of both groups together, 55.62\% of the patients had a mild and $27.22 \%$ had a moderate pain score. NRS score decreased with time in each group.

Conclusions: The pain intensity and the need for analgesics were less in the subcostal biopsies. Since intense pain and anxiety may be the cause of loss of the patients after the first biopsy, a subcostal biopsy could be preferred primarily.
\end{abstract}

Keywords: Image-guided biopsy, liver, pain, ultrasound

Nows owadays, despite the advanced imaging modalities, tru cut biopsy remains the gold standard in the diagnosis of liver parenchymal diseases $[1,2]$. Percutaneous liver biopsy is fundamental for the histological diagnosis, staging, and assessment of response to therapy in diffuse liver parenchymal diseases. Ultrasonography (US)-guided biopsy is the most accu- rate and cost-effective method and provides more specimens with less pain to patients [3]. The incidence of serious complications is less than $1 \%$, and the complications following percutaneous liver biopsy are well documented in a multicentre retrospective study on 68278 biopsies [4, 5]. Pain is known as the most frequent reason for patient discomfort following 
biopsy. $20 \%$ of patients had moderate, $16 \%$ of patients had severe pain and about $10 \%$ of patients wouldn't tolerate another biopsy in the future [6]. The reported moderate and severe pain generally requires hospitalization and is observed in $1-5 \%$ of the patients $[7,8]$, but some studies revealed that more than $50 \%$ of patients had moderate and severe pain following the procedure [9-11]. Pain is a very subjective and complex sensation and difficult to analyze, it is located at the biopsy puncture, radiating to the right shoulder, with mild to moderate intensity, and relives gradually $[6$, 12].

Although liver biopsy is a frequently used procedure, a consensus has not been reached on the best approach subcostal versus intercostal [9, 13, 14]. Hepatitis $\mathrm{C}$, younger age, the experience of the operator, the number of punctures were addressed as predisposing factors of pain. Severe pain sensation may induce anxiety that is another factor to increase pain intensity after percutaneous liver biopsy [11], it's, therefore, an outstanding matter to control the pain of the patients after the biopsies as well as to improve liver biopsy techniques worldwide. However, variances in biopsy techniques, preferred anesthesia/analgesia type, underlying liver disease of the patients of the studies may result in different conclusions. Comparison of severity of pain in subcostal and intercostal liver biopsy technique is not widely studied in the literature. This randomized study aims to compare pain intensity between the intercostal and subcostal techniques of US-guided liver biopsy in patients with diffuse liver disease.

\section{METHODS}

\section{Study design}

The study approval was obtained from the ethics committee. Comparing the pain intensity by a Numeric Rating Scale (NRS) between the intercostal and subcostal techniques of US-guided Tru-Cut liver biopsy in diffuse liver diseases was the main objective.

\section{Patient selection}

All liver patients referred for ultrasound-guided biopsy between March 2016 and May 2017 to the interventional radiology unit were assessed in a state hospital. All participants who have not inclusion cri- teria were excluded at the screening. All biopsies were performed by one board-certified interventional radiologist with 17 years of experience in US-guided biopsy. At a dedicated outpatient interventional radiology clinic, the screening and enrollment process was performed by analysis of medical records and if there are abdominal imaging studies. Any history of prior liver percutaneous core biopsy was explored by reviewing medical records. If there is, Ultrasound, CT, and MR images were reviewed at the hospital PACS system to identify the safest liver core biopsy approach. Selecting the participants who met the inclusion criteria were done by the interventional radiologist.

The study inclusion criteria were 1) age of $>18$ years, 2) clinical indication of liver biopsy for a nonfocal liver lesion, and 3) accepting the informed consent by the patients.

The exclusion criteria were as follows: 1) abnormal coagulation test results (with an international normalized ratio of $>1.5$ and a low thrombocyte number $(<70,000 / \mathrm{mm} 3)), 2)$ intrahepatic bile duct dilatation, 3) focal liver lesions, 4) hydatid cyst, 5) massive ascites, 6) previous liver transplantation, 7) patients who the biopsy can be done with only one of the two techniques, therefore, cannot be randomized. and 8) pregnancy.

\section{Randomization}

Two hundred forty-five patients were assessed for eligibility. After the exclusion of 37 patients, 208 cases were randomized into intercostal and subcostal groups. A computerized randomization system is used for patient selection. The assistant noted the pain score and, the patients were blind to the study method.

\section{Procedure}

\section{Before the biopsy}

All the study patients' liver biopsy indications were done clinically. They referred to the interventional radiologist. The indication of biopsy and complete blood count, and a coagulation profile including INR, APTT, platelets, and fibrinogen were re-analyzed and approved by the interventional radiologist. The patients were followed up daily following the biopsy. They were informed about the procedure and the possible complications and then asked to sign the consent form upon agreeing to participate in the study. The in- 
travenous line was inserted after the blood pressure and heart rate were measured. Moreover, the StateTrait Anxiety Inventory was used to measure each participant's trait and state anxiety level before the biopsy [15].

\section{During the biopsy}

The patients were transferred to the biopsy room. To maintain their full cooperation, no oral or intravenous analgesics or intra-procedure conscious sedation were given. Under sterile conditions, $20 \mathrm{ml}$ of $2 \%$ prilocaine hydrochloride (Pricain; Polifarma Pharmaceutical JSC. Tekirdag/Turkey) solution was injected ultrasound guided. Local anesthesia was done from the subcutaneous tissue to the liver capsule in the biopsy area by using a 25 -gauge needle. To obtain the optimal cooperation of the patients during the procedure, premedication or intra-procedure conscious sedation was not used.

The intercostal approach was performed from the right hemithorax inferolateral, and the subcostal approach was performed from the right side. A small incision of $<5 \mathrm{~mm}$ was made by a number 11 blade and the biopsy was done by an 18-gauge fully automated, biopsy needle (Bard MaxCore, Covington, GA) with the method of freehand US-guided biopsy. The cutting length of the needle was $22 \mathrm{~mm}$. In all cases, only one sample with one pass was taken and needle penetration depth into the liver was $2 \mathrm{~cm}$ from the liver capsule. (In case of the inadequate biopsy sample, $<15$ $\mathrm{mm}$ in length, the biopsy was repeated at the same entry side and the subject was excluded from the study. A simple wound dressing was applied after the procedure.

\section{After the biopsy}

Following the biopsy, all patients were transferred to the daycare unit and requested to lie on the biopsy side for $4 \mathrm{~h}$. The patients were followed up every $15 \mathrm{~min}$ of the first $2 \mathrm{~h}$ and every $30 \mathrm{~min}$ of the following $2 \mathrm{~h}$ in terms of the vital findings. If necessary, $500 \mathrm{mg}$ paracetamol (MINOSET ${ }^{\circledR} 500 \mathrm{mg}$ tablet, Bayer Turkish Chemical Industry, Ltd company Istanbul/Turkey) was administered. If the medication failed to control the pain, Diclofenac Sodium $75 \mathrm{Mg} / 3 \mathrm{Ml}$ (Dikloron, Deva Holding Ltd.) intramuscular analgesic would be ordered. The patients were discharged if there were no complications during the first $4 \mathrm{~h}$ after the biopsy. All the patients were instructed to contact a medical center immediately in case of any problems or complications. The electronic records and hospital referrals of all the patients were cross-checked for late complications upon completion of six months following the biopsy procedure.

\section{Statistical Analysis}

All statistical analyses were performed in MATLAB (R2016a, The MathWorks Inc., USA). Age and anxiety levels of patients in intercostal and subcostal groups were compared with Student's t-test. $\chi^{2}$ test was used to test any differences between treatment groups in means of sex ratio, liver biopsy history, final pathology results, need for additional analgesics. MannWhitney U test was used to compare pain scores of patients in intracostal and subcostal groups. The same tests were used to compare the parameters of male and female patients. The relationship between age and pain scores was evaluated with the Spearman rank-order correlation test.

\section{RESULTS}

Between March 2016 and May 2017, 245 participants were screened, and 231 were interviewed for enrollment at an outpatient interventional radiology clinic. A total of 37 participants were excluded due to the focal liver lesion, massive ascites, abnormal coagulation test results, etc. A total of 208 participants (mean age, 43.13 years; age range, 19-81 years; 124 females, 84 males) was randomly assigned to either the subcostal $(\mathrm{n}=104$; mean age, 43.08 years; age range, 19-81 years; 58 females, 46 males) or intercostal $(n=104$; mean age, 43.19 years; age range, 1979 years; 66 females, 38 males) arm. Of these participants, 10 did not undergo treatment because of biopsy cancellation $(n=8)$ or withdrawal of consent $(n=2)$.

Liver biopsy was done in 198 of the 208 randomly assigned participants. Demographics of patients undergoing US-guided liver biopsy are shown in Table 1. Groups were matched on age, gender, liver biopsy history, and final pathology results.

The primary aim of this study was to compare the pain level of participants within 0,2 , and 4 hours after the ultrasound-guided percutaneous liver biopsy pro- 
Table 1. Demographics and technical characteristics in per-protocol population

\begin{tabular}{|c|c|c|c|}
\hline Characteristic & $\begin{array}{c}\text { SC group } \\
\mathrm{n}=\mathbf{8 3}(\mathbf{4 9 . 1 1 \% )}\end{array}$ & $\begin{array}{c}\text { IC group } \\
\mathrm{n}=\mathbf{8 6}(\mathbf{5 0 . 8 9 \% )})\end{array}$ & $p$ value \\
\hline Mean Age \pm SD & $43.60 \pm 12.16$ & $44.05 \pm 11.84$ & $0.810 *$ \\
\hline Sex ratio (female/male) & $45 / 38$ & $56 / 30$ & $0.150 * *$ \\
\hline Previous liver biopsy history, $\mathrm{n}(\%)$ & & & $0.419 * *$ \\
\hline Yes & $11(0.13)$ & $8(0.09)$ & \\
\hline No & $72(0.87)$ & $78(0.91)$ & \\
\hline Final pathology result, $\mathrm{n}(\%)$ & & & $0.739 * *$ \\
\hline Diagnostic & $80(0.96)$ & $82(0.95)$ & \\
\hline Nondiagnostic & $3(0.04)$ & $4(0.05)$ & \\
\hline
\end{tabular}

$\mathrm{IC}=$ Intercostal, $\mathrm{SC}=$ Subcostal. $\mathrm{SD}=$ standard deviation, $*$ Student's t-test, $* *$ Mann-Whitney U test

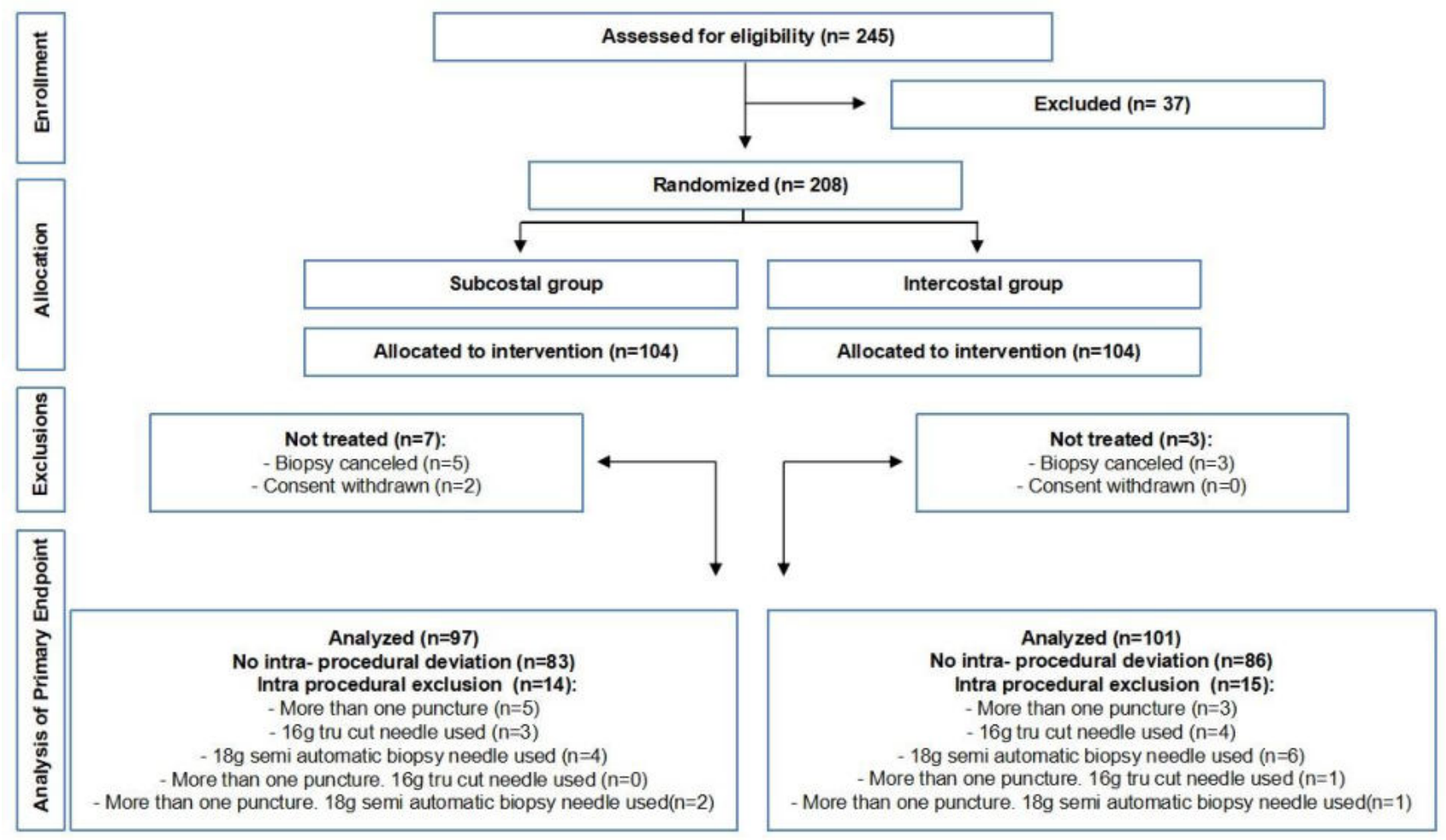

Fig. 1. Consort diagram.

cedure with either the subcostal or the intercostal approach.

The NRS was used to quantify pain. All patients declared that they would tolerate another biopsy if it was clinically required in the future. The median NRS scores, just after the procedure, 2 and $4 \mathrm{~h}$ later are summed up in Table 2.

Of the treated participants, fifteen patients in the intercostal group and fourteen patients in the subcostal group excluded due to more than one puncture, $16 \mathrm{~g}$ fully automated tru cut, or $18 \mathrm{~g}$ semi-automated tru cut needle use (because of different size and different sampling methods). The detail is seen in the consort diagram in Fig. 1.

Immediately after the biopsy $(p=0.0024)$, and at the $2^{\text {nd }}$ hour $(p=0.0298)$, NRS of the subcostal group was significantly less than the intercostal group. No significant difference was found in the pain level between the intercostal and subcostal groups 4 hours after the procedure ( $p=0.0787)$. No significant differ- 
Table 2. Pain dissipation after US-guided percutaneous tru-cut liver biopsy.

\begin{tabular}{|c|c|c|c|c|c|c|}
\hline & $\begin{array}{c}\text { IC group } \\
(\mathrm{n}=\mathbf{8 6})\end{array}$ & $\begin{array}{c}\text { SC group } \\
(\mathbf{n}=\mathbf{8 3})\end{array}$ & $p$ value & $\begin{array}{l}\text { M patients } \\
(\mathrm{n}=68)\end{array}$ & $\begin{array}{c}\text { F patients } \\
(\mathrm{n}=101)\end{array}$ & $p$ value \\
\hline Anxiety level ${ }^{[\mathrm{a}]}$ & $\begin{array}{c}39.74 \pm \\
9.86\end{array}$ & $37.47 \pm 11.16$ & $0.1617^{[\mathrm{b}]}$ & $40.00 \pm 10.54$ & $\begin{array}{c}37.70 \pm \\
10.50\end{array}$ & $0.1657^{[\mathrm{b}]}$ \\
\hline $\begin{array}{l}\text { Just after the } \\
\text { biopsy }{ }^{[c]}\end{array}$ & $3[1-5]$ & $2[1-3]$ & $0.0024^{[\mathrm{d}]}$ & 2 & 2 & $0.4673^{[\mathrm{d}]}$ \\
\hline 2nd-hour ${ }^{[c]}$ & $1.5[0-3]$ & $1[0-2]$ & $\mathbf{0 . 0 2 9 8}^{[\mathrm{d}]}$ & 1 & 1 & $0.5692^{[\mathrm{d}]}$ \\
\hline 4th-hour ${ }^{[\mathrm{c}]}$ & $0[0-2]$ & $0[0-1]$ & $0.0787^{[\mathrm{d}]}$ & 0 & 0 & $0.3414^{[\mathrm{d}]}$ \\
\hline \multicolumn{7}{|c|}{ Additional analgesics, $\mathrm{n}(\%)$} \\
\hline Tablet & $28(0.326)$ & $16(0.193)$ & $0.0492^{[\mathrm{e}]}$ & 16 & 28 & $0.5424^{[\mathrm{e}]}$ \\
\hline IM Amp & $15(0.174)$ & $4(0.048)$ & $0.0094^{[\mathrm{e})}$ & 9 & 10 & $0.5010^{[\mathrm{e}]}$ \\
\hline
\end{tabular}

ence was found between male and female patients regarding pain level. The need for additional oral and intramuscular analgesics after the biopsy was 28 and 15 out of 86 patients in the intercostal group, respectively; 16 and 4 out of 83 patients in the subcostal group, respectively.

The requirement for additional analgesics was significantly less in the subcostal group than the intercostal group (oral analgesic: $p=0.0492$; intramuscular analgesic: $p=0.0094$ ). At the evaluation of both groups together, $55.62 \%$ of the patients had a mild and $27.22 \%$ had a moderate pain score. Median NRS decreased with time in each group. We did not find any correlation between NRS scores and age neither in different treatment groups nor post-operative times. Besides, there were no significant differences between intracostal and subcostal groups in anxiety levels ( $p=$ $0.1617)$. Finally, when male and female patients were compared, no significant differences were found in any parameter (see Table 2).

Minimal external hemorrhage due to compression failure of skin dress was observed in one patient in the subcostal study group, but no intervention was required. No late complications were observed in any of the patients.

\section{DISCUSSION}

We performed a randomized study to compare the pain level of percutaneous US-guided parenchymal liver biopsy within 0,2 , and 4 hours after biopsy when the intercostal or subcostal approaches were used. From March 2016 to May 2017, 245 potential study participants were assessed for enrollment. A total of 208 participants were randomly assigned to the subcostal $(n=104)$ or intercostal $(n=104)$ arm. A total of 169 participants underwent treatment without intraoperative exclusion (mean age, 43.83 years; age range, 19-81 years; 101 females, 68 males); subcostal ( $\mathrm{n}=$ 83 ; mean age, 43.60 years; age range, $19-81$ years; 45 females, 38 males $)$ or intercostal $(n=86$; mean age, 44.05 years; age range, 22-79 years; 56 females, 30 males). The results of our study showed that both intercostal and subcostal biopsies were less painful similar to previous studies $[6,10,12,14,16,17]$. Moreover, pain intensity and the need for analgesics were more in the intercostal biopsies. The probable reasons are: (1) the intercostal approach may result in a pleural puncture, which is a sensitive epithelial layer; (2) the intercostal approach may traumatize the respiratory muscles; (3) respiratory movement during the intercostal approach acts in a contrary direction to the needle movement, which can cause more damage to the liver capsule. Conversely, in the subcostal approach, the needle versus respiratory movements is in the same direction, and this condition can cause less capsular damage; (4) injury of the periosteum of the ribs, which is sensitive to pain, and (5) intercostal nerve trauma are possible [6]. Both methods necessitate peritoneal puncture. Technically, the right subcostal liver biopsy can be relatively difficult because 
of the oblique course of biopsy needles. However, the complications were not found to be different in the current study. Subcostal biopsies are technically successful, nevertheless, this approach might not be preferred for patients with Chilaiditi syndrome, which is a rare anomaly with a $0.025 \%-0.28 \%$ of incidence [11]. In such cases, the right intercostal or the left subcostal approach can be used.

Although, the combination of sedation and analgesia could have a synergistic effect on reducing the pain during the biopsy procedure, however, result in partial amnesia and loss of corporation $[18,19]$ that could be challenging during the local anesthesia and biopsy. In this mean, to maintain the full cooperation of the patients during local anesthesia and biopsy, no systemic sedation or analgesia was administered in this study. If local anesthesia is applied well and biopsy is performed in the same tract that is infiltrated with lidocaine, the procedure will be almost painless and thus eliminate premedication risks. The well-innervated liver capsule is sensitive to pain sensation. So, effective administration of local anesthetics to this area plays an essential role in reducing pain during the biopsy. In the current study, $55.62 \%$ of the patients had mild and $27.22 \%$ of the patients had moderate pain score levels following biopsy that was similar to the previous studies (Table 3 ). The variables affecting pain after biopsy remain mostly unknown. Because the same intervention could result in different pain intensities in different participants. Although a consensus

Table 3. Brief review of the literature studying of pain after percutaneous liver biopsies

\begin{tabular}{|c|c|c|c|c|c|c|}
\hline $\begin{array}{l}\text { Study } \\
\text { (year) }\end{array}$ & $\begin{array}{c}\text { Number } \\
\text { of patients }\end{array}$ & Biopsy & $\begin{array}{l}\text { Mean pain } \\
\text { scale }\end{array}$ & $\begin{array}{c}\text { Used } \\
\text { analgesics/sedation }\end{array}$ & $\begin{array}{l}\text { Size of the } \\
\text { needle, } \\
\text { technique }\end{array}$ & $\begin{array}{l}\text { Predisposing } \\
\text { factors of pain }\end{array}$ \\
\hline $\begin{array}{l}\text { Castera et al. } \\
{[10]} \\
(1999)\end{array}$ & 30 & parenchymal & $\begin{array}{c}28 \\
(\mathrm{VAS})\end{array}$ & 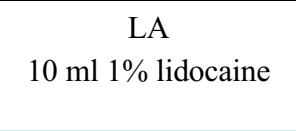 & $\begin{array}{l}\text { Menghini } \\
\text { Technique }\end{array}$ & $\begin{array}{l}\text { Hepatitis } \mathrm{C} \text {, young } \\
\text { age }\end{array}$ \\
\hline $\begin{array}{l}\text { Cadranel et } \\
\text { al. [9] } \\
(2000)\end{array}$ & $>2000$ & $\begin{array}{c}\text { mostly } \\
\text { parenchymal }\end{array}$ & $\begin{array}{c}28 \\
\text { (VAS) }\end{array}$ & varied & varied & $\begin{array}{l}\text { Female, hepatitis C; } \\
\text { (Pain less in } \\
\text { experienced } \\
\text { physician, general } \\
\text { anesthesia) }\end{array}$ \\
\hline $\begin{array}{l}\text { Riley et al. } \\
{[14]} \\
(2002)\end{array}$ & 121 & miscellaneous & Not given & $\begin{array}{c}\text { LA } \\
1 \% \text { lidocaine }\end{array}$ & Not given & $\begin{array}{l}\text { Hepatitis C, young } \\
\text { age, history of iv } \\
\text { drug use }\end{array}$ \\
\hline $\begin{array}{l}\text { Eisenberg et } \\
\text { al. }[11] \\
(2003)\end{array}$ & 54 & miscellaneous & $\begin{array}{c}42 \\
\text { (VAS) }\end{array}$ & $\begin{array}{c}5 \mathrm{mg} \text { diazepam (po, } 1 \\
\mathrm{~h} \text { before) } \\
\text { LA } \\
10 \mathrm{ml} 2 \% \text { lidocaine }\end{array}$ & $\begin{array}{c}16 \mathrm{G} \\
\text { automated tru- } \\
\text { cut }\end{array}$ & $\begin{array}{c}\text { Female, high anxiety } \\
\text { level }\end{array}$ \\
\hline $\begin{array}{l}\text { Tan et al. [6] } \\
(2005)\end{array}$ & 70 & parenchymal & Not given & $\begin{array}{l}1 \mathrm{mg} \text { midazolam }+50 \\
\mu \mathrm{gr} \text { fentanyl } \\
5-10 \mathrm{ml} \mathrm{1} \% \text { lidocaine }\end{array}$ & $18 \mathrm{G}$ & Female \\
\hline $\begin{array}{l}\text { Lindner et al. } \\
{[16]} \\
(2014)\end{array}$ & 223 & $\begin{array}{l}\text { parenchymal } \\
\quad(\mathrm{n}=85) \\
\text { focal lesion }(\mathrm{n} \\
\quad=113)\end{array}$ & $\begin{array}{c}2.98 \\
(\mathrm{NRS})\end{array}$ & $\begin{array}{c}\text { LA } \\
\text { scandicain 1\% }\end{array}$ & $\begin{array}{c}\text { Trucut } \\
\text { (mostly } \\
\text { subcostal) }\end{array}$ & $\begin{array}{l}\text { Parenchymal biopsy } \\
\text { had more pain } \\
\text { compared to focal } \\
\text { lesions, females, } \\
\text { young age }\end{array}$ \\
\hline $\begin{array}{l}\text { Baig et al. } \\
{[17]} \\
(2015)\end{array}$ & 50 & not given & $\begin{array}{c}2.7 \pm 1.11 \\
(\operatorname{VAS}[0-4])\end{array}$ & $\begin{array}{l}10 \mathrm{ml} 2 \% \text { xylocaine } \\
\text { +adrenaline }\end{array}$ & $\begin{array}{c}18 / 16 \mathrm{G} \\
\text { automatic } \\
\text { Trucut }\end{array}$ & Younger age, male \\
\hline $\begin{array}{l}\text { Pezeshki Rad } \\
\text { et al. }[12] \\
(2018)\end{array}$ & 112 & $\begin{array}{l}\text { parenchymal } \\
\text { and focal } \\
\text { lesion }\end{array}$ & $\begin{array}{l}17.86 \\
\text { (VAS) }\end{array}$ & $\begin{array}{c}\text { LA } \\
10 \mathrm{ml} \% \text { lidocaine }\end{array}$ & $16 \mathrm{G}$ & Intercostal biopsy \\
\hline Current study & 169 & parenchymal & $\begin{array}{c}1.68 \\
(\mathrm{NRS})\end{array}$ & $\begin{array}{c}\text { LA } \\
10 \mathrm{ml} 1 \% \text { lidocaine }\end{array}$ & $18 \mathrm{G}$ & Intercostal biopsy \\
\hline
\end{tabular}

$\mathrm{LA}=$ Local anesthesia, VAS $=$ Visual analog scale, $\mathrm{NRS}=$ Numeric rating scale 
does not exist [7], operators' manual skills and experience play a great role in reducing pain during and after the biopsy $[4,11,20,21]$. Nonskilled hands could not finish the biopsy procedure in a single deep inspiration of the patient, and rebreathing of the patient during the biopsy may cause more trauma to the liver capsule and parenchyma, resulting in more pain. The reduction of the biopsy needle gauge and the number of biopsy and/or entries was reported to reduce complications and pain [9], on the other hand, the needle's size must be regulated to obtain enough sample size for histopathological analysis [22]. The use of Tru-cut needles as opposed to the Menghini-style aspiration needles was reported to be associated with higher pain intensity, but this finding was considered controversial [7]. In contradiction, neither number of the passes and the size of the needle, nor subcostal/intercostals biopsy were found to be different in Lindner et al.'s [16] study. To ensure that this conflict does not affect the results of the study, the cases with more than one puncture and also the cases with a different type or gauge of biopsy needles were excluded because of different size and different sampling methods.

Liver biopsies are found to be more painful in patients with Hepatitis $\mathrm{C}$ infection, younger age, or history of intravenous drug use [14]. However, Tan et al. [6] found no significant difference in terms of pain in Hepatitis B/C and biopsy pass numbers. Castera et al. [10], Eisenberg et al. [11], Riley [14], Lindner et al. [16], and Baig and Javed [17] showed that pain scores are related to patients' age. It has been detected less pain in patients older than 50 years of age as it was previously explained as an adaptation to stress and painful events [16]. While older patients have undergone liver biopsy more for focal liver lesions rather than a diffuse parenchymal disease, younger patients have undergone biopsy more for the parenchymal disease. Meanwhile, whether the young age or parenchymal disease or both play a part in the intensity of pain $[6,11,13,16]$ is a controversial point. Whereas, Baig and Javed [17] found men had more intense pain after a biopsy. However, our study, just like Pezeshki Rad et al. [12] found no gender or age predilection.

The assessment of pain poses a significant problem in clinical practice and clinical research because of the subjective nature of pain perception [23]. The measurement of pain severity with the visual analog scale (VAS), NRS, and verbal rating scale (VRS) are accepted as accurate and current, but VAS has lower rates of completion and success than NRS in older patients [24]. Similar difficulties were observed in patients having a high dose of opioids [25]. Moreover, both VAS and NRS showed better sensitivity than VRS, which has fewer categories for pain assessment [26].

The common conclusion reached in all studies is; the intensity of pain felt after the percutaneous liver biopsy may differ from mild to moderate. While it is felt most intensely right after the biopsy, the intensity of pain decreases in the following 2 to 4 hours $[6,12$, $16]$.

Recently, Pezeshki Rad et al. [12] compared pain intensity in intercostal and subcostal biopsies in focal and diffuse parenchymal liver diseases, similar to our results, pain score was less in the subcostal group; $10 \%$ of the intercostals group, $3.33 \%$ of the subcostal group patients required intravenous analgesics. We did not administer intravenous analgesics but the need for oral or intramuscular analgesics was less in the subcostal group. Differently, to our study, pain intensity was similar just after the biopsy but significantly less in the 2nd and 4th hour. Tan et al. [6] used the VAS assessment score, compared the intercostal with the left subcostal method, and found no significant differences between the two groups; although they subjectively observed that the intercostals group seemed to have more pain and their post-procedural analgesic requirement was higher in the intercostal group $(27 \%$ vs. $36.4 \%$ ), it was not statistically significant ( $p=$ 0.64). In the study by Eisenberg et al. [11], $1 \mathrm{mg}$ of intravenous midazolam and $50 \mathrm{mg}$ of fentanyl was administered to all of their patients before biopsy unless they were contraindicated.

During parenchymal liver diseases, repeated biopsies may be needed. Severe pain and anxiety may be the cause of the loss of the patients after the first biopsy. From the patients' perspective, perception and compliance to liver biopsy are becoming a crucial issue for clinical management. The subcostal approach was found to be more suitable in US-guided liver biopsy.

Further randomized studies will be needed to evaluate the effectiveness of subcostal route versus intercostal regarding pain assessment. Despite advances in technology, there are potential gaps in our knowledge about pain perception in the liver biopsy. 


\section{Limitations}

The subjective nature of pain and retrospective analysis which could have caused a possible selection bias is a limitation in our study. All the liver biopsies were done in a single-center and by the same interventional radiologist which is inferior to a multicenter randomized controlled trial.

\section{CONCLUSION}

In conclusion, we found a statistically significant difference in the pain score level and subsequent need for oral or intramuscular analgesics 0 and $2 \mathrm{~h}$ after percutaneous liver biopsy via the intercostal or subcostal approach. Our study suggests that a subcostal approach can be effective in reducing the pain score level and subsequent need for analgesics after a percutaneous needle biopsy.

\section{Authors' Contribution}

Study Conception: YT; Study Design: YT; Supervision: YT; Funding: YT; Materials: YT; Data Collection and/or Processing: YT, ID; Statistical Analysis and/or Data Interpretation: YT, ID; Literature Review: YT, BA; Manuscript Preparation: YT, BA and Critical Review: YT, BA, İD.

\section{Conflict of interest}

The authors disclosed no conflict of interest during the preparation or publication of this manuscript.

\section{Financing}

The authors disclosed that they did not receive any grant during the conduction or writing of this study.

\section{REFERENCES}

1. Aribaş BK, Arda K, Çiledağ N, Aktaş E, Yakut F, Kavak S, et al. Accuracy and safety of percutaneous US-guided needle biopsies in specific focal liver lesions: comparison of large and small needles in 1300 patients. Panminerva Med 2012;54:233-9.

2. Howlett DC, Drinkwater KJ, Lawrence D, Barter S, Nicholson T. Findings of the UK national audit evaluating image-guided or image-assisted liver biopsy. Part I. Procedural aspects, diagnosticadequacy, and accuracy. Radiology 2012;265:819-31.

3. Papini E, Pacella CM, Rossi Z, Bizzarri G, Fabbrini R, Nardi

$\mathrm{F}$, et al. A randomized trial of ultrasound-guided anterior sub- costal liver biopsy versus the conventional Menghini technique. J Hepatol 1991;13:291-7.

4. Piccinino F, Sagnelli E, Pasquale G, Giusti G. Complications following percutaneous liver biopsy. A multicentre retrospective study on 68,276 biopsies. J Hepatol 1986;2:165-73.

5. McGill DB, Rakela J, Zinsmeister AR, Ott BJ. A 21-year experience with major hemorrhage after percutaneous liver biopsy. Gastroenterology 1990;99:1396-400.

6. Tan KT, Rajan DK, Kachura JR, Hayeems E, Simons ME, Ho CS. Pain after percutaneous liver biopsy for diffuse hepatic disease: a randomized trial comparing subcostal and intercostal approaches. J Vasc Interv Radiol 2005;16:1215-9.

7. Janes $\mathrm{CH}$, Lindor KD. Outcome of patients hospitalized for complications after outpatient liver biopsy. Ann Intern Med 1993;118:96-8.

8. Perrault J, McGill DB, Ott BJ, Taylor WF. Liver biopsy: complications in 1000 inpatients and outpatients. Gastroenterology 1978;74:103-6.

9. Cadranel JF, Rufat P, Degos F. Practices of liver biopsy in France: results of a prospective nationwide survey. For the Group of Epidemiology of the French Association for the Study of the Liver (AFEF). Hepatology 2000;32:477-81.

10. Castéra L, Nègre I, Samii K, Buffet C. Pain experienced during percutaneous liver biopsy. Hepatology 1999;30:1529-30.

11. Eisenberg E, Konopniki M, Veitsman E, Kramskay R, Gaitini D, Baruch Y. Prevalence and characteristics of pain induced by percutaneous liver biopsy. Anesth Analg 2003;96:1392-6.

12. Pezeshki Rad M, Abbasi B, Morovatdar N, Sadeghi M, Hashemi K. Pain in percutaneous liver core-needle biopsy: a randomized trial comparing the intercostal and subcostal approaches. Abdom Radiol 2019;44:286-91.

13. Mayoral W, Lewis JH. Percutaneous liver biopsy: what is the current approach? Results of a questionnaire survey. Dig Dis Sci 2001;46:118-27.

14. Riley TR 3rd. Predictors of pain medication use after percutaneous liver biopsy. Dig Dis Sci 2002;47:2151-3.

15. Spielberger, C. D. Anxiety as an emotional state. In: Spielberger C. D (editor). Anxiety: Current trends in theory and research Vol. 1, New York, NY, USA: Academic Press; 1972. pp. 3-19.

16. Lindner A, Frieser M, Heide R, Wildner D, Neurath MF, et al. Postinterventional pain and complications of sonographically guided interventions in the liver and pancreas. Ultraschall Med 2014;35:159-65.

17. Baig MA, Javed W. Pain associated with liver biopsies through percutaneous approach under sonographic guidance-a cross sectional pilot study in a tertiary care hospital. J Ayub Med Coll Abbottabad 2015;27:45-7.

18. Brouillette DE, Yoo YK, Chien MC, Rabinovitz M, Tarter RE, Van Thiel DH. Use of midazolam for percutaneous liver biopsy. Dig Dis Sci 1989;34:1553-8.

19. Alexander JA, Smith BJ. Midazolam sedation for percutaneous liver biopsy. Dig Dis Sci 1993;38:2209-11.

20. Menghini G. One-second needle biopsy of the liver. Gastroenterology 1958;35:190-9.

21. Froehlich F, Lamy O, Fried M, Gonvers JJ. Practice and complications of liver biopsy. Results of a nationwide survey in 
Switzerland. Dig Dis Sci 1993;38:1480-4.

22. Scheuer PJ. Liver biopsy size matters in chronic hepatitis: bigger is better. Hepatology 2003;38:1356-8.

23. Jensen MP, Karoly P. Self-report scales and procedures for assessing pain in adults. In: Turk DC, Melzack R, eds., Handbook of Pain Assessment. New York, NY, USA: The Guilford Press; 2010: pp.19-44.

24. Lund I, Lundeberg T, Sandberg L, Budh CN, Kowalski J, Svensson E. Lack of interchangeability between visual analogue and verbal rating pain scales: a cross sectional description of pain etiology groups. BMC Med Res Methodol 2005;5:31.

25. Jensen MP, Turner JA, Romano JM. What is the maximum number of levels needed in pain intensity measurement? Pain 1994;58:387-92.

26. Cardella JF, Kundu S, Miller DL, Millward SF, Sacks D; Society of Interventional Radiology. Society of Interventional Radiology clinical practice guidelines. J Vasc Interv Radiol 2009;20(7 Suppl):S189-91. 